\title{
Use of electroplating industry sludge as a construction material
}

\begin{abstract}
There are a large number of electroplating industries. The effluent treatment plant of these electroplating industries produces a huge quantity of sludge, which basically comprises of metal precipitates. Since these metals being hazardous in nature, their disposal is the big problem. Technologies being widely used to solve the problem of disposal of hazardous wastes are stabilization and solidification. In stabilization some supporting media, binder or other modifier are added to the waste, so that the contaminated particles are fully or partially replaced with each other. The physical nature (engineering properties) of waste is altered by employing additives. The objective of the present study is to study stabilization and solidification of electroplating industry sludge and then to study the engineering behavior of this stabilized and solidified sludge. Finally the possibility of using this stabilized and solidified sludge as a construction material is being explored.
\end{abstract}

Keywords: chromium, toxic metal, concrete, waste management, mortar, solidification
Volume 2 Issue I - 2017

Kanwar Varinder,' John Siby ${ }^{2}$

'Department of Civil Engineering, Chitkara University, India ${ }^{2}$ Department of Civil Engineering, Punjab Engineering College, India

Correspondence: Kanwar Varinder, Registrar, Chitkara University, Himachal Pradesh, HIMUDA Education Hub, Barotiwala, Distt Solan- 74 I03Himachal Pradesh, India, Email varinderkanwar@gmail.com

Received: December 19, 2016 | Published: February 08, 2017

\section{Introduction}

Every industrial unit generates wastes along with the processed goods. These wastes actually represent loss of the valuable material and energy from the production processes and investment in the pollution control. Usual approach followed by the industries, to cope with the problem of wastes and pollution, is use of waste treatment systems as end-of-pipe remedies. The remedies adopted often result in the removal of pollution from one source and placing the pollutants somewhere else, such as, a landfill. This approach to wastes is expensive and involves wasteful use of resources. As wastes are also resources but out of place, the approach followed by the industries should give due consideration to the waste generation side in addition to the treatment of the wastes. The right approach for industrial pollution department is to employ a waste management scheme that uncovers all opportunities for in plant reduction/control of pollution and use waste treatment systems as end-of-pipe remedies only for the unavoidable waste streams of the industry.

Industrial systems are linear systems taking in raw material and giving out products and wastes. In their effort to minimize negative impact on environment, industries have been traditionally collecting and treating the wastes before disposal. This approach, i.e. endof-pipe approach, to wastes has been resulting in the removal of pollutants from one medium and placing in some other medium rather than reducing/removing the polluting potential of wastes leading to the wasteful spending of resources. Further waste management by this approach is proving to be a burden on the industry. The magnitudes of limitations associated with end-of-pipe approach have recently been forcing the industries to examine this approach critically and adopt an alternative waste reduction approach. The present study aims at providing an alternative to this approach.

Waste reduction approach is leading to environment friendly processes and technology. Pollution prevention approach can be considered as one step ahead of waste reduction approach. It integrates both waste reduction approach and end-of-pipe treatment approach and involves implementation (in a balanced manner) of waste management priority hierarchy of the following four strategies:

a. Source reduction/elimination of wastes.

b. Recovery, recycling and reuse of wastes.

c. End-of-pipe treatment of wastes.

d. Disposal of wastes.

In view of the potential of pollution prevention approach and the non-availability of relevant literature, development/articulation/ synthesis of a procedure/protocol for the development, implementation and maintenance of pollution prevention programs in industrial facilities has been felt very much needed for introducing the use of pollution prevention approach in electroplating industry. In order to make protocol/procedure practicable and usable by the industry, there is also a need to validate and refine it through its experimental application in selected industrial units. Present study is an attempt in this direction.

Our industry sector is presently facing the problems of pollution and scarcity of raw material and energy. For orienting this unsustainable sector towards sustainability and making it compatible for symbiotic coexistence with the natural ecosystem, human settlements and agricultural systems, there is an urgent need to concentrate our efforts on conservative and efficient use of raw material and on waste minimization/ reduction. The processes employed vary widely from industry to industry and even within the same industry from unit to unit. So, proper waste management in industries may require case-by-case critical environmental analysis of industrial units and development of specific integrated waste management scheme for industrial units. In the present work, study of stabilization and solidification of electroplating sludge is carried out, the engineering behavior of this stabilized and solidified sludge is found and possibilities of using this as a construction material are explored. 


\section{Waste management in case of electroplating industry sludge}

Waste management scheme in essence includes two aspects, namely in plant control strategies and end-of-pipe remedies for wastes. In plant Control Strategies

The electroplating industry is subject to a variety of changing business conditions. Two of the most significant factors are the increase in costs of materials, such as plating chemicals and process water and the environmental considerations, which include the need to control the discharge of effluent waste in streams and the disposal of hazardous wastes. The survival of any metal finishing companies will depend on how effectively they deal with the impact of these changes and requirements.

The in plant control strategies in electroplating industry are broadly divided into the following major categories:

I. Inventory Management.

II. Production processes modification.

III. Metal recovery from rinse water.

IV. A plant assessment includes the following steps.

a. Inspect the plating room layout

b. Review plant-operating practices.

c. Examine process water use.

Conduct sampling and laboratory analysis to characterize waste streams and to determine drag- out rates.

Identify the frequency, volume, and characteristics of batch dumps.

End of Pipe Remedies to the Wastes Generated (Chromium Reduction)

Segregation and mixing of waste streams: The waste water streams originating in an electroplating industry may be the result of degreasing, acid dip/picking, alkali dip/cleaning, plating process etc. These waste streams result from rinsing at various stages, dumping of exhausted tank contents and miscellaneous reasons such as spills, splashes, wash down etc. The waste stream generally contains: 1) impurities immiscible in water such as greases, oils and solvents; 2) metals, metal salts and metal complexes (including chromate and cyanides); 3 ) various acids and alkalis.

Proper segregation/mixing of various waste streams become important for increasing the technological and economic feasibility of treatment and disposal of wastes for resources recovery. Because of the hazardous nature (specially streams containing cyanides and chromium), proper segregation and mixing of waste streams is all the more important in electroplating industries. The streams containing cyanides and chromium are always separated from other waste streams. The mixing of these streams with the rest is done only after the requisite treatment. Segregation of wastewater streams (containing cyanide and chromium) should be ensured in the case of spills, splashes and wash downs.

\section{Chrome reduction}

Precipitation removal of chromium as hydroxide sludge requires reduction of hexavalent chromium to trivalent chromium. By reducing $\mathrm{Cr}^{6+}$ to $\mathrm{Cr}^{3+}$, the toxicity of the metal will be reduced by a factor of about 1000. Various chemicals that can alternatively be used for reduction of hexavalent chromium to trivalent chromium are:

I. Sulphur dioxide

II. Sodium bisulfite.

III. Ferrous sulphate

IV. Sodium hydrosulfite.

\section{Hydrazine solution.}

Sulphur dioxide reduction process is applicable to process liquors with concentration ranging from 20 to $30 \mathrm{gm} / \mathrm{liter}$ and to rinse water containing chromium up to $600 \mathrm{mg} /$ liter. $^{1}$ The method is more suitable for larger installations. It is cost competitive (needs less acid to maintain $\mathrm{pH}$ ). The disadvantage of this method is that it increases the salinity of treated wastewater.

Because of operational ease, sodium bisulfate is preferred in smaller systems though it is more expensive (more acid is required to maintain $\mathrm{pH}$ ). In addition to cost, another disadvantage of using sodium bisulfate is that these chemicals need careful storage in dry areas away from oxidants, such as, dichromate and chromic acid. Ferrous sulfate method is not very widely used because of inefficiency, high costs and sludge generation rate. It is generally used in cases where hexavalent chromium concentrations are low. In some cases, where flow are very low, iron and steel scrap along with sulfuric acid is used for the reduction, despite the fact that it requires extremely large quantity of scrap. Sodium hydrosulfite is used in special circumstances, especially for treating small batches and spills. The operational $\mathrm{pH}$ in this case is in the range of 8 to 9 . It also demands extra care in storage and handling.

$\mathrm{Cr}^{6+}$ can be reduced by treating the wastewater with excess of hydrazine at 1.4 to $1.7 \mathrm{pH}$ and 40 to $50^{\circ} \mathrm{C}^{2}$ Because of health hazards (inhalation and ingestion is hazardous; the chemical can be absorbed through skin; and liver and kidney are most vulnerable) the use of hydrazine for chromium reduction has declined.

\section{Using sludge in construction industry}

This can be achieved through stabilization and solidification. The objectives of stabilization and solidification would encompass both the reduction in waste toxicity and mobility as well as an improvement in the engineering properties of stabilized material. ${ }^{3}$ The present study also emphasis on this type of end of pipe remedies to the wastes generated.

\section{Stabilization \& solidification}

Stabilization and solidification have been widely applied in the management of hazardous wastes. The technologies are being applied to:

a. The remediation of hazardous waste sites.

b. The treatment of residue from other treatment processes.

c. The treatment of contaminated land where large quantities of soil containing contaminants are encountered.

In general, stabilization is a process where additives are mixed with waste to minimize the rate of contaminant migration from the waste and reduce the toxicity of the waste. The stabilization may be described as a process by which contaminants are fully or partially bound by the addition of supporting media, binders, or other modifier. ${ }^{4}$ Likewise, solidification is a process employing additives by which the physical nature of waste (as measured by the engineering properties 
of strength, compressibility, and/or permeability) is altered during the process. ${ }^{5}$ Thus, objectives of stabilization and solidification would encompass both the reduction in waste toxicity and mobility as well as an improvement in the engineering properties of stabilized material. ${ }^{3}$

Fixation is often used synonymously with stabilization. Stabilization is accomplished through the addition of reagents that. ${ }^{6}$

I. Improve the handling and physical characteristics of the waste

II. Decrease the surface area across which transfer or loss of contaminants can occur.

III. Limit the solubility of any pollutants contained in the waste.

IV. Reduce the toxicity of the contaminants

In contrast, solidification is described as a process by which sufficient quantities of solidifying material, including solids are added to the hazardous material to result in a solidified mass of material. Solidifying the mass is accomplished through the addition of reagents that:

a. Increase the strength.

b. Decrease the compressibility.

c. Decrease the permeability of the waste.

During stabilization, certain contaminants may be destroyed such as by the decolorization of chlorinated hydrocarbons. Other organics may disappear as a result of volatilization. Stabilization must be considered as a waste treatment process that reduces, to an acceptable or geologically slow rate, the movement of contaminants into the environment.

\section{Applications of stabilization technologies} are. ${ }^{8}$

The three major areas of application for stabilization technologies

I. Land disposal-the stabilization of wastes prior to secure landfill disposal.

II. Site remediation-the remediation of contaminated sites.

III. Solidification of industrial wastes-the solidification of nonhazardous, unstable wastes, such as sludge.

\section{Land disposal}

The land disposal of liquid waste increases the likelihood of contaminant migration. Liquid waste, along with wet sludge, must be stabilized prior to land filling. To effectively stabilize liquids, the stabilization agents cannot be absorbents (such as sawdust). The liquid absorbed by agents could be easily released in the landfill when compressed under additional loads. That is, as more material is land filled, the weight of overlying material would squeeze the liquids out of underlying material. Therefore, the stabilization reagents

Table I Properties of cement used must chemically and physically bind the liquid so that they are not expelled by the consolidation stresses or leached out by the downward percolation of precipitation. ${ }^{9}$

\section{Site remediation}

The remediation of contaminated sites having organic wastes, inorganic wastes, and/or contaminated soils may be accomplished employing stabilization technology. For site remediation, stabilization is used to 1) improve the handling and physical characteristics of the wastes, 2) decrease the rate of contaminant migration by decreasing the surface area across which the transfer of pollutant can occur and by limiting the solubility of pollutant, and 3 ) reduce the toxicity of certain contaminants. Stabilization may be considered to be a more permanent remedial solution than other alternative such as containment. Stabilization is particularly well suited for sites where the hazard involving large quantities of soils contaminated at low levels. ${ }^{10-15}$ In many instances it may not be environmentally sound or cost effective to excavate, transport and landfill or incinerate soil contaminated with low level of pollutants because of:

a. The additional air pollution caused by excavation equipment, trucks and the exposure of buried contaminated soils to the air, which enhances the volatilization of organics.

b. The increased risks as a result of traffic accidents.

\section{Solidification of industrial waste}

As a legacy from our past waste management practices, a wide variety of organic and inorganic industrial wastes can be found in pits, ponds and lagoons. Solidification (affecting of physical properties such as strength and compressibility) improves the engineering properties and may reduce the rate at which contaminants migrate into the environment. Although many of the non-hazardous waste materials may not endanger the public health or the environment, the materials are frequently structurally unstable, aesthetically unsuitable, and their condition precludes other uses of the site area. Thus the primary goal of the solidification is the improvement of structural integrity of the material. For such solidification projects, the effectiveness of the solidification process can often be evaluated by measurement of material strength.

\section{Experimental programme \\ Properties of materials}

The cement used was 43 grade Cement. It was tested in laboratory for its properties as per Indian Standards IS: 4031-1988 (Part VI). Its physical characteristics are represented in Table 1. Locally available river sand was used as fine aggregates. The sample of sand was taken and results of its sieve analysis (grading of sand), specific gravity, moisture content and percentage water absorption are given in Table 2. The sieve analysis was carried out as per IS: 2386 (Part- I) and tests results were such that the sand confirmed to Zone II, according to IS: 383-1970.

\begin{tabular}{llll}
\hline Sr. no. & Characteristics & Value & Value as per IS: 8 I I 2 - I989 \\
\hline I & Specific Gravity & 3.1 & - \\
2 & Fineness (as \%age retained on 90 micron sieve) & 5 & $<10$ \\
3 & Standard Consistency & $30 \%$ & -- \\
4 & Initial Setting Time & 134 minutes & 30 minutes (minimum) \\
5 & Final Setting Time & 258 minutes & 600 minutes (maximum) \\
6 & Compressive Strength after 28 days & $48 \mathrm{~N} / \mathrm{mm} 2$ & $43 \mathrm{~N} / \mathrm{mm} 2$ \\
\hline
\end{tabular}


Locally available crushed stone aggregate in which rounded gravel was also present has been used in the entire work. Maximum nominal size of coarse aggregate was $20 \mathrm{~mm}$. The aggregate was tested for specific gravity, fineness modulus and percentage water absorption. The results are given in Table 2. The sludge used in the experiment was obtained from a local industry (Punjab, India) and it was the sludge taken from chrome plating unit of that industry. First of all chemical analysis of the sludge was done and the results obtained are shown in Table 3. Ordinary tap water which is fit for drinking, was used in preparing all the concrete mixes in the investigation. ${ }^{16}$

Table 2 Characteristics of aggregates

\begin{tabular}{llll}
\hline S. no. & Characteristics & Fine aggregate & $\begin{array}{l}\text { Coarse aggregate } \\
(20 \mathrm{~mm} \text { size) }\end{array}$ \\
\hline I & Specific Gravity & 2.63 & $2.61 \mathrm{for} \mathrm{SSD}$ \\
2 & Water Absorption & $0.40 \%$ & $1.10 \%$ \\
3 & Fineness Modulus & $215 \%$ & 5.8 \\
4 & Grading Zone & II & - \\
5 & Unit Weight & $18 \mathrm{KN} / \mathrm{m}^{3}$ & $16.3 \mathrm{KN} / \mathrm{m}^{3}$ \\
\hline
\end{tabular}

Table 3 Characteristics of electroplating industry sludge

\begin{tabular}{lll}
\hline Sr. no. & Characteristics & Value \\
\hline 1 & Specific Gravity & 1.64 \\
2 & Moisture & $50.40 \%$ \\
3 & Ash & $92.9^{*}$ \\
4 & Nickel & $0.004^{*}$ \\
5 & Total Chromium & $2.04^{*}$ \\
6 & Cr ${ }^{+6}$ & $0.94^{*}$ \\
7 & Cr & $1.1^{+3}$ \\
8 & Oil \& Grease & $8.3 \mathrm{mg}$ per 100gm* \\
9 & Total Organic Matter & $12.8 \% *$ \\
\hline
\end{tabular}

*Values are on Oven Dry solid basis

\section{Moulds}

Standard cast iron moulds of size $7.5 \mathrm{~cm}$ and $15 \mathrm{~cm}$ cube size were used for casting the specimens.

\section{Mortar Mix}

The mortar mix used was 1:3. The quantities of each mix designed are tabulated in Table-4. Ordinary tap water was used for the preparation of mortar specimens and also for curing for a period of 7 and 28 days. The water added was calculated after making correction for the moisture present in the sludge. For each mortar mix 6 cubes of size $75 \mathrm{~mm} \times 75 \mathrm{~mm} \times 75 \mathrm{~mm}$ were cast for compression testing at 7 and 28 days.

\section{Concrete Mix}

The concrete mixtures were designed using IS method of mix design. M20 \& M30 mix of concrete was used. The quantities of mix designed are tabulated in Table $5 \& 6$. Ordinary tap water was used for the preparation of concrete specimens and also for curing for a period of 7, 14 and 28 days. The water added was calculated after making correction for the moisture present in the sludge. For each concrete mix 9 cubes of size $150 \mathrm{mmx} 150 \mathrm{mmx} 150 \mathrm{~mm}$ were cast for compression testing at 7,14 and 28 days.

Table 4 Quantity of material for different mortar mixtures

\begin{tabular}{lllllll}
\hline MIX & MI & M2 & M3 & M4 & M5 & M6 \\
\hline $\begin{array}{l}\text { \% Replacement of fine } \\
\text { aggregate with sludge }\end{array}$ & 0 & 5 & 7.5 & 10 & 12.5 & 15 \\
Cement (gm) & 1200 & 1200 & 1200 & 1200 & 1200 & 1200 \\
Sludge (gm) & 0 & 180 & 270 & 360 & 450 & 540 \\
Fine Aggregate (gm) & 3600 & 3420 & 3330 & 3240 & 3150 & 3060 \\
Water (gm) & 504 & 504 & 504 & 504 & 504 & 504 \\
\hline
\end{tabular}

Table 5 Quantity of material for different concrete mixtures (M20)

\begin{tabular}{llllll}
\hline MIX & CI & C2 & C3 & C4 & C5 \\
\hline $\begin{array}{l}\text { \% Replacement of fine aggregate } \\
\text { with sludge }\end{array}$ & 0 & 10 & 20 & 30 & 40 \\
$\begin{array}{l}\text { Cement }\left(\mathrm{Kg} / \mathrm{m}^{3}\right) \\
\text { Sludge }\left(\mathrm{Kg} / \mathrm{m}^{3}\right)\end{array}$ & 268 & 268 & 268 & 268 & 268 \\
Coarse Aggregate $\left(\mathrm{Kg} / \mathrm{m}^{3}\right)$ & 0 & 33 & 66 & 99 & 132 \\
Fine Aggregate $\left(\mathrm{Kg} / \mathrm{m}^{3}\right)$ & 651 & 651 & 651 & 651 & 651 \\
Water $\left(\mathrm{Kg} / \mathrm{m}^{3}\right)$ & 330 & 297 & 264 & 231 & 198 \\
\hline
\end{tabular}

Table 6 Quantity of material for different concrete mixtures (M30)

\begin{tabular}{llllll}
\hline MIX & C6 & C7 & C8 & C9 & C10 \\
\hline $\begin{array}{l}\text { \% Replacement of fine } \\
\text { aggregate with sludge }\end{array}$ & 0 & 10 & 20 & 30 & 40 \\
Cement $\left(\mathrm{Kg} / \mathrm{m}^{3}\right)$ & 477 & 477 & 477 & 477 & 477 \\
Sludge $\left(\mathrm{Kg} / \mathrm{m}^{3}\right)$ & 0 & 53 & 106 & 159 & 212 \\
Coarse Aggregate $\left(\mathrm{Kg} / \mathrm{m}^{3}\right)$ & 1160 & 1160 & 1160 & 1160 & 1160 \\
Fine Aggregate $\left(\mathrm{Kg} / \mathrm{m}^{3}\right)$ & 530 & 477 & 424 & 371 & 318 \\
Water $\left(\mathrm{Kg} / \mathrm{m}^{3}\right)$ & 186 & 186 & 186 & 186 & 186 \\
\hline
\end{tabular}

\section{Mode of failure}

All the test specimens were loaded upto failure load. The crack appearance and the type of failure were noted. Cracks were seen to start from one of the loaded faces and then propagating to opposite loading face. Even after the appearance of this very first crack, the test specimens continue to take more loads thus causing formation of more cracks and fine hair cracks branching out of these main cracks till complete failure. During test it was observed that in most of cases the failure is due to bonding between cement, sand, coarse aggregate and sludge.

\section{Source of errors}

Utmost care was taken in performing the tests for the investigation. However, errors could not be eliminated fully to provide an ideal investigation. The possible sources of error are described below: 
i. Curing temperature was fluctuating and slightly lower than that required to follow IS: $516-1959$ specification (i.e. $27 \pm 2^{\circ} \mathrm{C}$ ).

ii. Sludge was obtained from industry two to three times, and every time it was not possible to check all its properties. So, it may be possible that the some of properties of sludge obtained at different times might have changed.

\section{Results and discussions}

The results of the investigation are plotted in Figures 1-6. Figure 1 shows the development of compressive strength of mortar with age. It has been observed from this figure that the mortar specimens of Mix M1 show highest strength value at all ages.

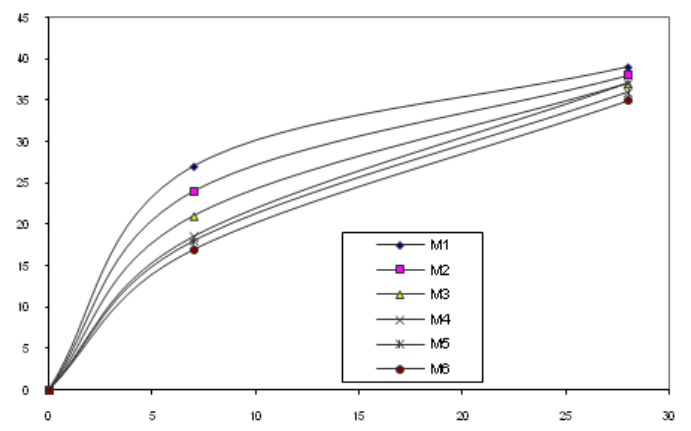

Figure I Compressive strength of mortar specimens at $7 \& 28$ days age.

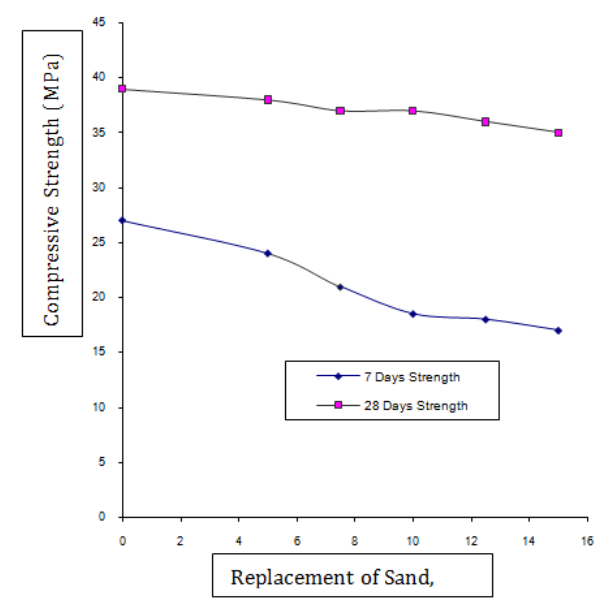

Figure 2 Variation of compressive strength of mortar specimens with \% age replacement of sand.

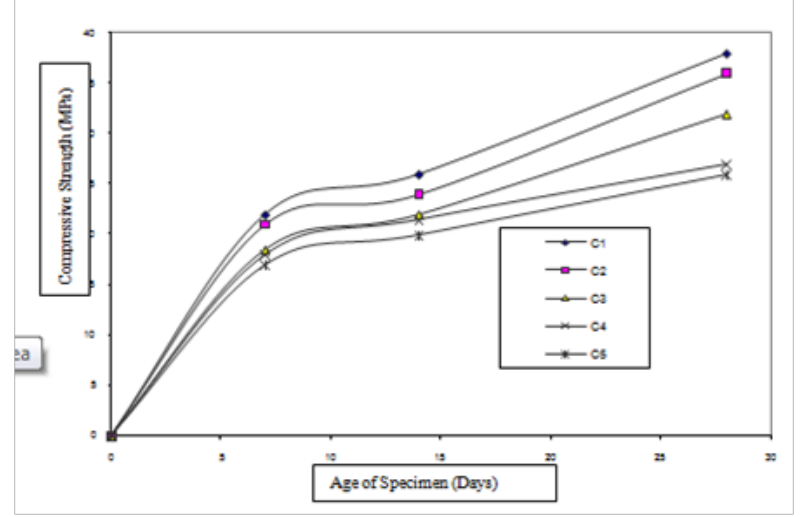

Figure 3 Compressive strength development in concrete specimens (M20) at $7,14 \& 28$ days age.

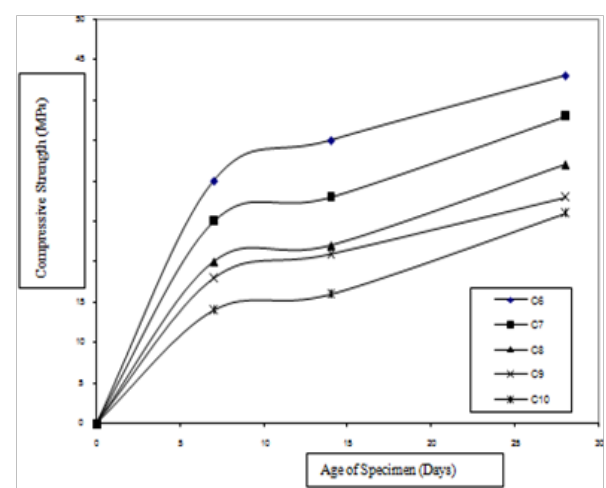

Figure 4 Compressive strength development in concrete specimens (M30) at $7,14 \& 28$ days age.

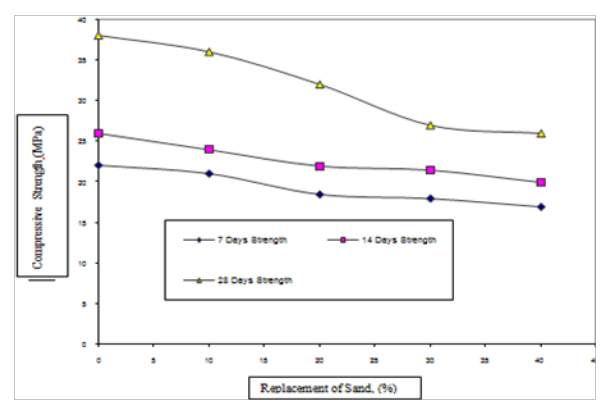

Figure 5 Variation in compressive strength of concrete specimens with \% age replacement of sand [M20].

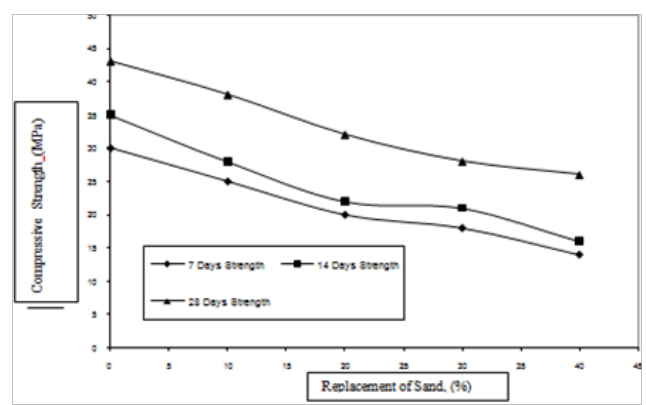

Figure 6 Variation in compressive strength of concrete specimens with \% age replacement of sand [M30].

The trend of strength development exhibited by mortar specimens containing sludge has been similar to that of specimens containing no sludge. However, as the percentage of sludge increased a consistent drop is observed in the strength values. The 7 days compressive strength value with $15 \%$ replacement of fine aggregate with sludge is $18.5 \%$ lower than that of reference mix containing no sludge. The drop in the corresponding 28 days compressive strength value is $10.2 \%$. The replacement of fine aggregate with sludge is thus causing a significant drop in the 7 days and 28 days compressive strength of mortar specimens.

Figure 2 shows the effect of replacement level of sludge on the compressive strength of mortar specimens. It has been observed that the influence of the increasing sludge replacement level is much less on the 28 days compressive strength as compared to 7 days compressive strength.

Figure 3 shows the development of compressive strength in concrete specimens (M20 Grade) with age. Specimens of control mix with no sludge content show highest compressive strength values at 
all ages. The strength obtained at 28 days is higher than the target strength of M20 concrete mix. Replacing a part of sand with sludge causes a drop in 7 days, 14 days \& 28 days strength values, but the strength development curves remain similar to that of reference mix. The drop in 7 days and 28 days compressive strength of a mix with $10 \%$ replacement of sand with sludge as compared with reference mix is about $10 \%$, whereas the drop in 7 days and 28 days compressive strength of a mix with $40 \%$ replacement of sand with sludge as compared with reference mix is $22.7 \%$ and $31.5 \%$, respectively.

Figure 4 shows the development of compressive strength in concrete specimens (M30 Grade) with age. Specimens of control mix with no sludge content show highest compressive strength values at all ages. The strength obtained at 28 days is higher than the target strength of M30 concrete mix. Replacing a part of sand with sludge causes a drop in 7 days, 14 days $\& 28$ days strength values, but the strength development curves remain similar to that of reference mix. The drop in 7 days and 28 days compressive strength of a mix with $10 \%$ replacement of sand with sludge as compared with reference mix is $16.67 \%$ \& $11.6 \%$, respectively, whereas the drop in 7 days and 28 days compressive strength of a mix with $40 \%$ replacement of sand with sludge as compared with reference mix is $53.3 \%$ and $39.5 \%$, respectively.

Effect of replacement level of sludge on compressive strength of concrete (M20 Grade) is shown in Figure 5. It is observed from this figure that maximum drop in compressive strength is observed at $40 \%$ replacement level of sludge. For this replacement level the drop in the 7 days compressive strength as compared to the reference mix specimens is $22.7 \%$. The drop in the corresponding 14 and 28 days compressive strength is $23.1 \%$ and $31.5 \%$, respectively.

Effect of replacement level of sludge on compressive strength of concrete (M30 Grade) is shown in Figure 6. It has been observed from this figure that maximum drop in compressive strength is observed at $40 \%$ replacement level of sludge. For this replacement level the drop in the 7 days compressive strength as compared to the reference mix specimens is $53.3 \%$. The drop in the corresponding 14 and 28 days compressive strength is $54.3 \%$ and $39.5 \%$, respectively.

It is thus observed that replacement of sand with sludge has more influence on the 28 days compressive strength of concrete specimens as compared to 7 days and 14 days strengths. The drop in the 28 days compressive strength of M20 grade of concrete as compared to the reference mix with sludge replacement levels of $10,20,30$, and $40 \%$ is observed to be $5.3 \%, 15.8 \%, 28.5 \%$ and $31.5 \%$, respectively. The drop in the 28 day compressive strength of M30 grade of concrete as compared to the reference mix with sludge replacement levels of 10 20,30 , and $40 \%$ is observed to be $11.6 \%, 25.6 \%, 34.9 \%$ and $39.5 \%$, respectively. The 28 days compressive strength of concrete specimens falls below the target strength when the replacement level is 30 to $40 \%$.

\section{Conclusion}

i. The results of the present study indicate that electroplating industry sludge can be used as a replacement of sand in mortar as well as in concretes.

ii. No incompatibility problems were observed in the experiments carried out in the study.

iii. Replacement of sand with sludge causes a drop in the compressive strengths of the mortars and concretes; however, drop is not very high at low replacement levels. In mortar a replacement level of $15 \%$ causes a drop of $10 \%$ in 28 days compressive strength values. In concrete a replacement level of $20 \%$ causes a drop of $15.8 \%$ in 28 days compressive strength values.

iv. At $40 \%$ replacement level, mixing and casting also causes problems because the mix became too harsh.

v. The result thus indicate that sludge can be used to replace sand to the extent of $15 \%$ and $20 \%$ in mortars and concretes, respectively, where compressive strength requirement is not a crucial factor.

\section{Scope for Further Research}

The electroplating sludge contains a number of chemicals and thus may react with the other components of mortar and concrete. Environmental effect can also cause disintegration of the mortars and concretes made with the sludge. Thus a long-term study should be carried out to investigate the durability of mortars and concretes incorporating various amount of sludge.

\section{Acknowledgements}

None.

\section{Conflict of interest}

The author declares no conflict of interest.

\section{References}

1. Okopnaya NT, et al. Use of $\mathrm{SO}_{2}$ to treat chromium Containing Wastewater. Soviet Journal of Water Chemistry and Technology. 1988;10(3):96-99.

2. Dikusar AI. Removal of Hexavalent Chromium from Electroplating. USSR SU $1715713 \mathrm{cl} \mathrm{COZ} \mathrm{F1/62} \mathrm{(Patent);} 1992$.

3. Culinane MJ. Handbook for Stabilization/Solidification of Hazardous Waste. US. Environmental Protection Agency Hazardous Waste Engineering Research Laboratory. 1986.

4. Conner JR. Chemical Fixation and Solidification of Hazardous Wastes. New York: Van Nostrand Reinhold; 1990. 692 p.

5. Pojasek RB. Ed: Toxic and Hazardous Wastes Disposal. Ann Arbor: Ann Arbor Science Publishers; 1979. 407 p.

6. Malone PG, Jones LW. Survey of Stabilization/Solidification of Hazardous Industrial Wastes. U.S. Environmental Protection Agency Hazardous Waste Engineering Research Laboratory. 1979. 41 p.

7. Truett JB. Feasibility of insitu Stabilization/Solidification of Land filled Hazardous Wastes. EPA/600/2-83/088. 1983.

8. Michael D Lagrega, et.al. Hazardous Waste Management. New York: McGraw-Hill; 1986.

9. Cartwrite PS. An update on Reverse Osmosis for Metal Finishing. Plating and Surface Finishing. 1984;71(4):62.

10. Chang LY, McCoy BJ. Waste Minimization for Printed Circuit Board Manufacture. Hazard Waste Handbook; 1990. 7:293.

11. Clarence HR. Waste Water Control and Treatment. New York: Electroplating Engineering Handbook (Ed) Durney; 1984.

12. Eason J, DeBishop. Pollution Control in the Electronics Industries. Material Finish. 1984;82(2):69.

13. Higgins TE. Hazardous Waste Minimization Handbook. USA: Lewis Publishers Inc; 1989. 
14. Ryder GA. Rinse Management Techniques. Material Finish Industry. 1986;84(11):23.

15. Singh Balbir. Waste Management in Electroplating Industry a Case Study. Patiala: ME Thesis submitted to TIET; 1994.
16. Serious Reduction of Hazardous Waste U.S Office of Technology Assessment, Washington, DC, OTA-ITE-317. 1986. 